\title{
TanDEM-X MISSION: OVERVIEW, CHALLENGES AND STATUS
}

\author{
Manfred Zink, Alberto Moreira \\ German Aerospace Center (DLR), Microwaves and Radar Institute \\ Oberpfaffenhofen, Germany, E-Mail: manfred.zink@dlr.de
}

\begin{abstract}
TanDEM-X (TerraSAR-X add-on for Digital Elevation Measurement) opens a new era in spaceborne radar remote sensing [1]-[3], [9], [12]. A single-pass SAR interferometer with adjustable baselines in across- and in along-track directions was formed by adding a second (TDX), almost identical spacecraft to TerraSAR-X (TSX) and flying the two satellites in a closely controlled formation. With typical across-track baselines of 150 to $500 \mathrm{~m}$ a global Digital Elevation Model (DEM) with $2 \mathrm{~m}$ relative height accuracy at a $12-\mathrm{m}$ posting is being generated.
\end{abstract}

Index Terms - TanDEM-X, bistatic SAR formation, SAR interferometry, global Digital Elevation Model (DEM)

\section{MISSION OBJECTIVES}

TanDEM-X is the first bistatic SAR interferometer in space. Beyond the generation of a global TanDEM-X DEM as the primary mission goal, local DEMs of even higher accuracy level (posting of $6 \mathrm{~m}$ and relative vertical accuracy of $0.8 \mathrm{~m}$ ) and applications based on Along-Track Interferometry (ATI) like measurements of ocean currents are important secondary mission objectives. Along-track interferometry also allows for innovative applications to be explored and can be performed by the so-called dual-receive antenna mode on each of the two satellites and/or by adjusting the along-track distance between TSX and TDX to the desired value. Combining both modes provides a highly capable along-track interferometer with four phase centers. The different ATI modes can e.g. be used for improved detection, localization and ambiguity resolution in ground moving target indication and traffic monitoring applications. Furthermore TanDEM-X supports the demonstration and application of new SAR techniques, with focus on multistatic SAR, polarimetric SAR interferometry, digital beam forming and super resolution.

TanDEM-X has an ambitious time schedule to reach the main mission goal. After the commissioning phase, the first three years are dedicated to the global DEM acquisitions. To facilitate dual-baseline phase unwrapping all land masses have already been covered twice in the same looking direction but with different baselines. Difficult mountainous terrain requires additional acquisitions viewing from the opposite direction to allow filling gaps due to shadow and layover. The baseline geometry in these first years is optimized for DEM performance. A limited number of scientific acquisitions are being included during this mission phase depending on the available satellite resources and the suitability of the baseline values for fulfilling the scientific requirements. After DEM acquisition, a 6-month mission phase is foreseen for scientific experiments and demonstration of new interferometric techniques and applications.

\section{THE TanDEM-X SPACECRAFT}

The TDX satellite is a rebuild of TSX with only minor modifications. This offers the possibility for a flexible share of operational functions for both the TerraSAR-X and TanDEM-X missions among the two satellites [4].

During the last phase of the TSX spacecraft development, the SAR instrument design was extended to allow exchange of synchronization pulses to support coherent operation of both SAR instruments during bistatic operation. Six sync horns on each satellite provide a quasiomnidirectional coverage. An additional propulsion system based on high-pressure nitrogen gas is accommodated on TDX. This cold gas system provides smaller impulses than the hydrazine system on both satellites (which is used for orbit maintenance) and supports formation flying by fine orbit control of the TDX satellite. The TDX solid state mass memory capacity is 768 Gbit which is doubled compared with TSX to support the collection of the enormous amount of DEM data.

The TDX satellite is designed for a nominal lifetime of 5 years. Predictions for TSX based on the current status of system resources indicate at least two extra years (until the end of 2014) of lifetime, providing a minimum of 4 years of joint operation.

\section{THE GROUND SEGMENT}

The missions TerraSAR-X and TanDEM-X jointly share the same space segment consisting of the TSX and TDX satellites orbiting in close formation and are operated using 


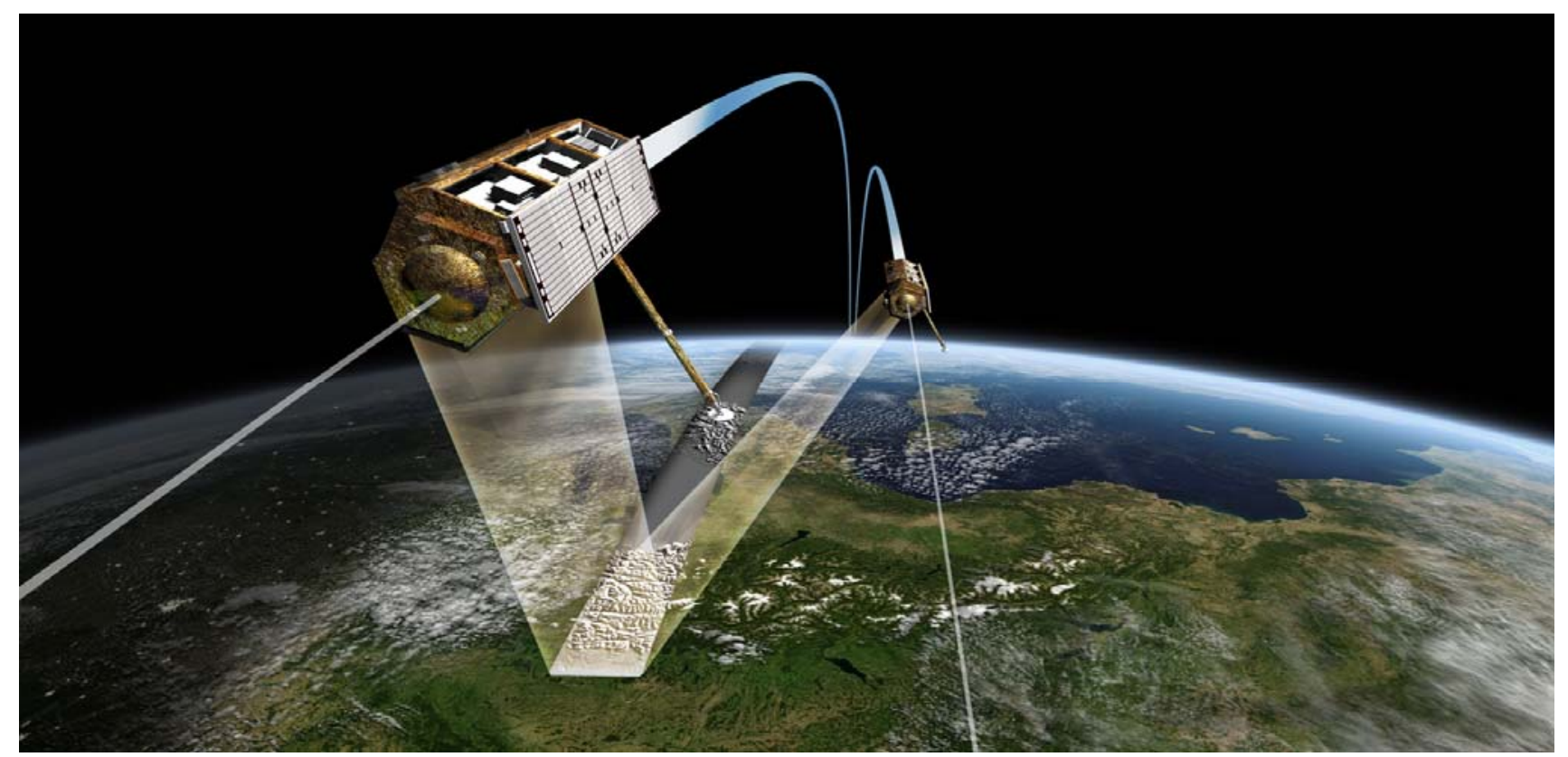

Fig. 1: TSX and TDX satellites flying in close formation over Italy and the Alps. With across-track baseline values ranging from 150 to $500 \mathrm{~m}$ a high-resolution global Digital Elevation Model is being generated.

a common ground segment, that was originally developed for TerraSAR-X and that has been extended for the TanDEM-X mission [5] - [8]. Specific new developments are described in the following.

The spatial baseline between the TSX and TDX is derived with millimeter accuracy from on-board GPS measurements taken by the two-frequency IGOR GPS receivers.

A key issue in operating both missions jointly is the different acquisition scenarios: whereas TerraSAR-X requests are typically single scenes for individual scientific and commercial customers, the global DEM requires a global mapping strategy. This strategy has also to account for the current formation flying geometry which, in turn, depends on the orbit parameters selected and for any given orbit configuration permits generating a digital elevation model only within a certain latitude range.

The two satellites downlink their data to a global network of ground stations: Kiruna in Sweden, Inuvik in Canada, and O'Higgins in the Antarctic. The global acquisitions for the digital elevation model alone absorb a data volume of more than 350 Terabytes. After a brief quality check, the data are recorded on tape and shipped to DLR in Oberpfaffenhofen for processing and archiving.

The entire processing chain is a new TanDEM-X specific development. Major design drivers result from the acquisition strategy which requires the combination of several (global) coverages and application of multi-baseline processing techniques based on supporting intermediate products. Absolute height calibration relies on a selected set of reference points of the globally distributed elevation data provided by the laser altimeter from NASA's ICESat mission.

\section{CLOSE FORMATION FLIGHT}

An orbit configuration based on a Helix geometry has been selected for safe formation flying. The Helix like relative movement of the satellites along the orbit is achieved by combination of an out-of-plane (horizontal) orbital displacement imposed by different ascending nodes with a radial (vertical) separation imposed by the combination of different eccentricities and arguments of perigee. Since the satellite orbits never cross, the satellites can be arbitrarily shifted along their orbits. This enables a safe spacecraft operation without the necessity for autonomous control. Cross- and along-track baselines ranging from $150 \mathrm{~m}$ to $10 \mathrm{~km}$ and from 0 to several $100 \mathrm{~km}$, respectively, can be accurately adjusted depending on the measurement requirement [7].

\section{MISSION STATUS AND OUTLOOK}

After the launch in June 2010 the monostatic commissioning phase was dedicated to calibration and performance verification and revealed calibration accuracies and overall performance of the TDX SAR system and its products as good as for TSX. After comprehensive testing of the various safety measures close formation was achieved mid October 2010 and the operations at typical distances between 150 and $500 \mathrm{~m}$ is running remarkably smooth and stable since then. 


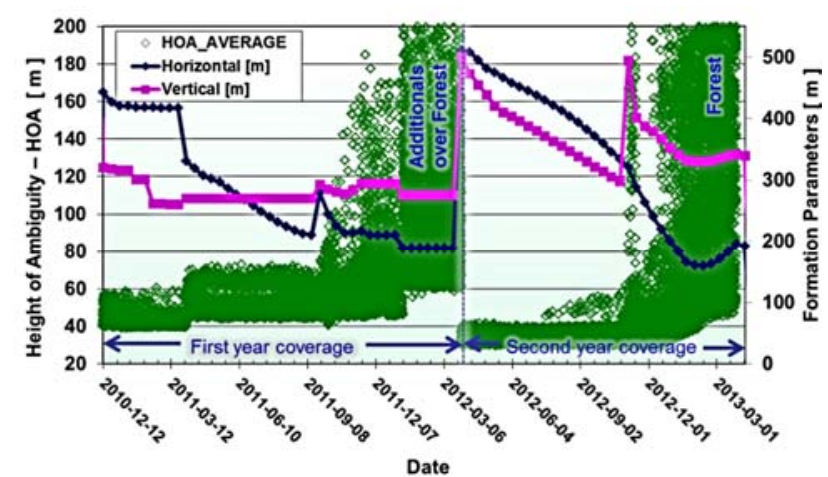

Fig. 2: Height of ambiguity in green and formation parameters (horizontal and vertical separation) for the first and second global acquisitions.

The subsequent bistatic commissioning phase of the TanDEM-X mission concentrated on checking out the complete bistatic chains from acquisition planning to bistatic and interferometric processing and generation of socalled raw DEMs. Global DEM acquisitions have started in December 2010 and the first global coverage (except Antarctica) was completed in March 2012. Parallel to the first month of operational data acquisition the team concentrated its efforts on the calibration of the bistatic interferometer. Correction of differential delays between TSX and TDX was necessary to facilitate the utilization of radargrammetry for resolving the $2 \pi$-ambiguity band. A comprehensive monitoring system has been established to evaluate the performance [11] of each individual data take and provides feedback to the TanDEM-X acquisition planning for additional acquisitions. In the meantime, delay and baseline calibration have reached such an accuracy level [10], that more than $90 \%$ of all so-called Raw DEMs are within $\pm 10 \mathrm{~m}$ of DEM derived from SRTM/ICESat data (see Fig. 3) already before the final calibration step using ICESat data as reference heights.

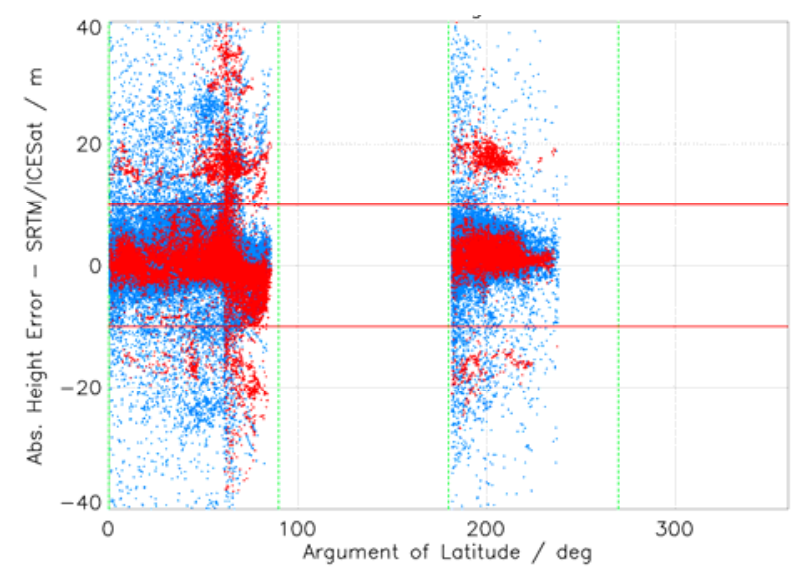

Fig. 3: Absolute height error (in comparison to SRTM and ICESat) for the scene based Raw DEMs (i.e. before final calibration using ICESat data as reference heights); blue: first year coverage, red: second year coverage.
Efforts currently concentrate on making the final calibration and mosaicking chain fully operational. Based on the first global acquisition so-called intermediate DEMs are being produced for larger regions. The second global coverage has been completed in March 2013. The current processing status of the second acquisition can be seen in the relative height error map [11] shown in Fig. 4. After a period of gap-filling the current acquisitions concentrate on Antarctica, which for reasons of better SNR has to be mapped during local winter conditions. Due to the orbit inclination of $98^{\circ}$ non-nominal left-looking operation is necessary to acquire inner Antarctica. Planning for the third or even fourth acquisitions over difficult terrain is in preparation. It is anticipated to finalize data acquisitions for the global DEM by mid-2014. First parts of the global TanDEM-X DEM will become available early 2014.

\section{CONCLUSION}

Accurate calibration of radar system delay, phase synchronisation between the TSX and TDX radar systems as well of the interferometric baselines have been successfully carried out showing excellent system performance. Following the nominal mission timeline, the first global interferometric acquisition has been completed in 2012 and the second one was completed by March 2013. After the mapping phase over Antarctic, additional interferometric acquisitions will be performed in highly mountainous areas. The results achieved so far are compliant to the expected performance for a global DEM with $2 \mathrm{~m}$ height accuracy. After the standard DEM acquisitions, DEMs of even higher accuracy will be produced for selected areas. In addition, interferometric acquisitions with even larger baselines can be adjusted for for the exploration and demonstration of scientific experiments.

TanDEM-X has demonstrated the feasibility of an interferometric radar mission with close formation flight and delivers an important contribution for the concept and design of future SAR missions [12]. One example is Tandem-L, a mission proposal for monitoring dynamic processes on the Earth surface with unprecedented accuracy [13] - [16].

\section{REFERENCES}

[1] Krieger, G., Moreira, A., Fiedler, H., Hajnsek, I., Werner, M., Younis, M., Zink, M.: TanDEM-X: A Satellite Formation for High Resolution SAR Interferometry. IEEE Transactions on Geoscience and Remote Sensing, vol. 45, no. 11, pp. 3317-3341, Nov. 2007.

[2] Moreira, A., Krieger, G., Hajnsek, I., Hounam, D., Werner, M., Riegger, S., Settelmeyer, E.: TanDEM-X: a TerraSAR-X addon Satellite for Single-Pass SAR Interferometry, Proceedings of the International Geoscience and Remote Sensing Symposium IGARSS, Ancorage, Alaska, 2004. 


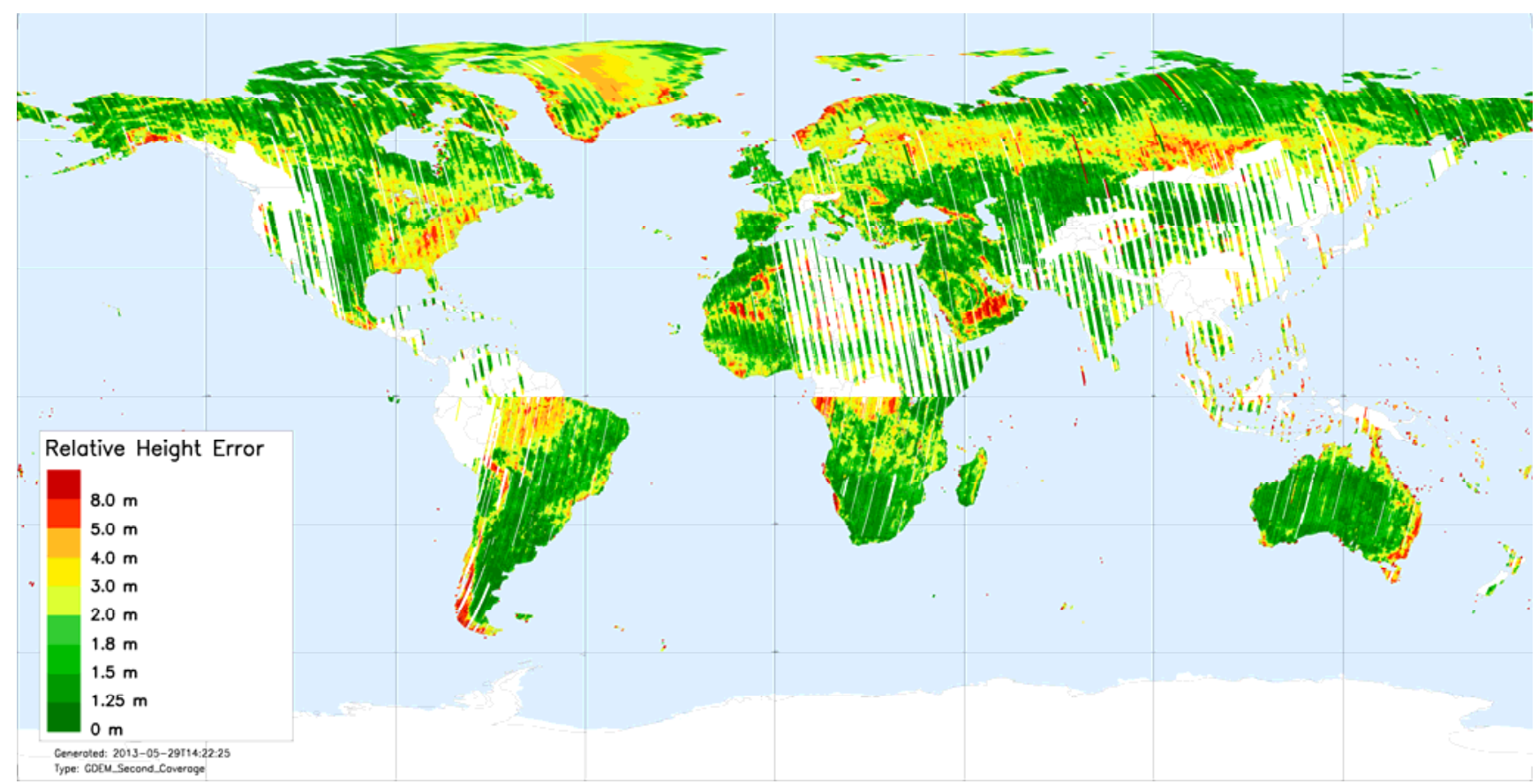

Fig. 4: Global relative height error map of the second global acquisition which was completed in March 2013. Processing status as of May 29, 2013.

[3] Zink, M., Bartusch, M., Ulrich, D.: TanDEM-X Mission Status. Proceedings of the European Conference on Synthetic Aperture Radar (EUSAR), Nuremberg, Germany, April 2012.

[4] Pitz, W., Miller, D.: The TerraSAR-X Satellite. IEEE Transactions on Geoscience and Remote Sensing, vol. 48, no. 2, pp. 615-622, Feb. 2010.

[5] Buckreuss, S., Schättler, B., The TerraSAR-X Ground Segment, IEEE Transactions on Geoscience and Remote Sensing, vol. 48, no. 2, pp. 623-632, Feb. 2010.

[6] Schättler, B., Kahle, R., Metzig, R., Steinbrecher, U., The Joint TerraSAR-X/TanDEM-X Ground Segment, Proc. IGARSS, , Vancouver, Canada, 24.-29. July 2011, pp. 2298 - 2301.

[7] Kahle, R., Schlepp, B.: Extending the TerraSAR-X Flight Dynamics System for TanDEM-X. 4th International Conference on Astrodynamics Tools and Techniques,, Madrid, Spain, 3.- 6. May 2010.

[8] Breit, H., Younis, M., Balss, U., Niedermeier, A., Grigorov, C., Hueso Gonzalez, J., Krieger, G., Eineder, M., Fritz, T.: Bistatic Synchronisation and Processing of TanDEM-X Data, Proceedings of IGARSS, Vancouver, Canada, 2011.

[9] Krieger, G. et al.: TanDEM-X. In: Distributed Space Missions for Earth System Monitoring, Chapter 13, Springer 2012, pp. $387-435$.

[10] Hueso González, J., Walter Antony, J.M., Bachmann, M., Krieger, G., Zink, M., Schrank, D., Schwerdt, M.: Bistatic System and Baseline Calibration in TanDEM-X to Ensure the Global
Digital Elevation Model Quality. ISPRS Journal of Photogrammetry and Remote Sensing, Volume 73, September 2012, pp. 3-11.

[11] Rizzoli, P., Bräutigam, B., Kraus, T., Martone, M., Krieger, G.: Relative Height Error Analysis of TanDEM-X Elevation Data. ISPRS Journal of Photogrammetry and Remote Sensing, Volume 73, September 2012, pp. 30-38.

[12] Rodriguez-Cassola, M., et al.: First Bistatic Spaceborne SAR Experiments with TanDEM-X. IEEE Geoscience and Remote Sensing Letters, vol. 9, no. 1, January 2012, pp. 33-37.

[13] Krieger, G., Hajnsek, I., Papathanassiou, K., Younis, M., Moreira, A.: Interferometric Synthetic Aperture Radar (SAR) Missions Employing Formation Flying. Proceedings of the IEEE, vol. 98, no. 5, 2010.

[14] Moreira, A. Hajnsek, I., Krieger, G., Papathanassiou, K., Eineder, M., De Zan, F., Younis, M., Werner, M.; Tandem-L: Monitoring the Earth's Dynamics with InSAR and Pol-InSAR. Proceedings of the Pol-InSAR Workshop, Frascati, Italy, 2009.

[15] F. Kugler, I. Hajnsek, K. Papathanassiou, Dual Pol-InSAR forest height estimation by means of TanDEM-X data, in: International Geoscience and Remote Sensing Symposium (IGARSS), Munich, Germany, 2012.

[16] K. Papathanassiou, F. Kugler, I. Hajnsek, Exploring the potential of Pol-InSAR techniques at X-band: results and experiments from TanDEM-X, in: International Geoscience and Remote Sensing Symposium (IGARSS), Munich, Germany, 2012. 